\title{
The better use of plant foods
}

\section{By B. J. F. Hudson and W. J. BRAY, Department of Food Science, University of Reading, London Road, Reading $R G \mathrm{I}{ }_{5} A Q$}

The examination of general food consumption trends in the UK during the past few decades reveals some well-recognized movements. Whilst our energy intake has increased very gradually to a point which is often regarded as excessive, the proportion derived from animal sources has increased markedly relative to that which is derived from vegetable foods. The proportion derived from carbohydrate has, not surprisingly, fallen in comparison with the proportion derived from fat. Further, the proportion of our protein derived from animal sources has also increased sharply in relation to our protein intake as a whole.

Considering this background it is possible to appreciate the reasons for exploring the better use of plant foods. The trend, through the 1950's and 1960's, towards an increased use of the more expensive animal products was mainly because we 'never had it so good', and the traditional British illusion that food was basically cheap and plentiful still persisted. The consumption of animal products became a matter of prestige in the context of the affluent society. In the 1970's this trend is being halted. Animal products may or may not be good for us, or indeed ethically acceptable, but they are certainly wasteful in terms of resource utilization and in the economics of production.

Table I. Yields ( $\mathrm{kg} / \mathrm{ha}$ per annum) of crude protein (nitrogen $\times 6.25)$ and edible oil

Field beans (Vicia faba) (UK)

Soya beans (USA)

Crude protein
$75^{\circ}$
735
525
460
430
380
159
159
138
87
1650
660
700

Edible oil

Protein conversion ${ }^{\bullet}(\%)$

Potatoes (USA)

Wheat (UK)

Millk (forage-fed cows)

Rapeseed (Brassica campestris) (UK)

Broilers (grain-fed)

Beef (forage-fed)

Eggs (grain-fed birds)

Sheep (forage-fed)

Lucerne (Medicago sativa)

Lucerne LPC (40\% extraction)

Lupinseed (Lupinus albus)

is) (UK)

LPC, leaf protein concentrate.

- Protein conversion $(\%)=\frac{\text { edible protein produced by animal }}{\text { protein consumed by animal }} \times 100$.

†As milk fat. 
In this country, more so than in many, we have to maximize our use of agricultural land, so that output per ha per annum is crucially important. Table I compares various crops from this point of view in terms of crude protein (nitrogen $\times 6.25$ ) productivity. Protein is taken here as the critical factor since energy supplies seem to be more easily and flexibly met.

We see at once that, if UK consumers were prepared to accept their protein, or a greater proportion of it, from vegetable sources, they could hope to obtain their nutritional requirements more cheaply, and further, with a less adverse effect on our balance of payments than is now the pattern. It is clear that if we could make better use of material that is now required in the form of feedstuffs an inefficient step in the protein to protein conversion process could be eliminated. Reference to feedstuffs requirements brings us to a related topic, our current demand for imported feedstuffs, as shown in Table 2.

Though we are sometimes led to believe that we are self-sufficient in terms of our production of, for example, dairy products, eggs, broilers and pigs, Table 2 shows that, unless we could rely on imports of soya beans and other oilseeds or meals and on fish meal we could not at present sustain these industries. Even rapeseed (Brassica campestris), during the period assessed, was almost entirely imported, though it is an arable crop which we can produce ourselves.

Table 2 also draws attention to our very vulnerable position in terms of edible oil requirements, at a time when consumers are demanding, in either a 'visible' or 'invisible' form, greater supplies than ever before. We are dependent almost wholly for our edible oil supplies on imported soya beans (Glycine max.), palm oil, rapeseed and other vegetable oils or oilseeds, and fish oil. We need, therefore, quite apart from protein, an appropriate source of home-produced vegetable oil.

We can therefore express our conclusions in the form of two propositions: ( $\mathrm{I}$ ) in order to achieve efficient home-production of protein requirements we should

Table 2. UK feedstuffs consumption (kg crude protein (nitrogen $\times 6.25)$ ), 1973-4 ( oint Consultative Organization, Ministry of Agriculture, Fisheries and Food, 1976)

$\begin{array}{lcc} & \text { Home-produced } & \text { Imported } \\ \begin{array}{l}\text { Energy feedstuffs } \\ \text { Cereals and products }\end{array} & 1257 & \\ \text { Protein concentrates } & - & 291 \\ \text { Oil cakes and meals } & 3 & 559 \\ \text { Rapeseed (Brassica campestris) } & 24 & 38 \\ \text { Field beans (Vicia faba) } & - & 57 \\ \text { Maize gluten } & 25 & - \\ \text { Dried grass } & 40 & 30 \\ \text { Urea } & 57 & 135 \\ \text { By-products } & 155 & 819 \\ \text { Animal protein } & 304 & 1110 \\ \text { Total concentrates } & 1561 & \$ 250000000 \\ \text { Total consumption } & & \end{array}$


concentrate mainly on the development of new sources of vegetable protein. This could be direct protein production in the form of concentrates, or double-purpose oilseed crops to produce edible oil as well as protein; (2) if we wish to continue to consume animal products as a major part of our diet, we should ensure that our feedstuffs requirements are substantially home-produced. Let us consider two crops which can, it is believed, substantially relieve our present problems if they are suitably developed and integrated into our agricultural and food-processing pattern.

\section{Lupinseed (Lupinus albus)}

Our strategy in choosing lupins (Lupinus albus and Lupinus angustifolius) as a new arable crop for intensive study in Reading was based on its potential as a second oilseed, after rapeseed, for Britain (Hudson, Fleetwood \& ZandMoghaddam, 1976). As a legume, already known to adapt to a very wide range of climatic conditions, it has minimal fertilizer requirements. Our traditional legume crop, the field bean (Vicia faba), unfortunately shows great variability in yield and has a negligible oil content. Soya beans cannot be reliably grown in our northern latitude, but a crop with rather similar characteristics, though more adaptable, could take advantage of the intensively studied agronomy as well as the wellestablished processing technology of soya beans.

As can be seen from Table 3, the composition of soya beans and lupini beans, a variety of Lupinus albus which is grown and marketed in Italy as a food commodity, are strikingly similar.

\section{Table 3. Compositions of dehulled seeds of various oilseeds}

Component

Protein ( $/ \mathrm{kg})$

Oil $(\mathrm{g} / \mathrm{kg})$

Component fatty acids

(mg/g total fatty acids)

16:0

18:0

18:1

$18: 2$

$18: 3$

22:1

Others

\section{Soya beans \\ (Glycine max.)}

380

200

$\begin{array}{r}110 \\ 40 \\ 250 \\ 520 \\ 80 \\ - \\ \hline\end{array}$

Lupini beans

(Lupinus albus)

$35^{\circ}$

120
Rapeseed (Brassica
campestris var. Canbra)
200
400

50

10

580

180

20

60

100

Values for the popular low-erucic acid (22:1) variety of rapesced (Brassica campestris), Canbra, are shown also for comparison. Protein contents are very satisfactory in lupinseed. Protein quality remains to be fully evaluated. Our analytical results had shown that there are significant inter-species differences in essential amino-acid profiles. Most species are limiting in methionine and cysteine but one, Lupinus luteus, is limiting in valine: lupinseeds in general compare favourably with soya beans. In vitro digestibility studies give values of 
approximately 0.95 and, though protease inhibitors are present, they occur at lower levels than in soya beans.

Oil contents, generally, are low in comparison with soya beans, and will have to be raised significantly, say to approximately $180 \mathrm{~g} / \mathrm{kg}$, before extraction of the seed by conventional processing methods becomes economic. However, since seed breeding programmes have not, until now, been aimed in the direction of increasing oil content, there is every possibility that this can be achieved.

Oil quality is just as important as yield, and this is governed by the amounts and types of component fatty acids. Even though erucic acid, a compound which has been shown to produce disturbing symptoms when fed to experimental animals, is greatly reduced in the rapeseed variety Canbra as compared with ordinary rapeseed oil, it is not eliminated. It is present only in traces in some Lupinus species. Linolenic acid $(18: 3)$, an undesirable component in terms of sensory quality, is no higher in lupinseed generally than in soya beans or rapeseed. No objection can be made to the other component fatty acids.

Perhaps the main objection to lupinseed as a food or food component is its wellknown content of toxic quinolizidine alkaloids. Despite this, 'bitter' lupinseed continues to be used as an edible bean in several countries where the need to eliminate or at least reduce the alkaloid level by water leaching is traditionally recognized. It is less well known that, in at least three important species, alkaloid contents have been almost eliminated by selective breeding. We have examined, qualitatively and quantitatively, the alkaloid profiles of many species and cultivars. Primitive varieties such as the lupini bean can contain from 20 to $30 \mathrm{mg}$ alkaloids/g seed. Such levels have been greatly reduced: for example, Kievsky Mutant, a Lupinus albus cultivar, contains only $0.05 \mathrm{mg}$ total alkaloids/g. Such socalled 'sweet' varieties can, in general, be classed as non-toxic.

If a new food crop, like lupinseed, is to be fully exploited, processing opportunities must be thoroughly explored. Fortunately, during the last two decades, such dramatic advances have been made in soya-bean technology that this aspect can hardly be regarded as a venture into the unknown. The extraction, refining and hydrogenation of soya-bean oil are carried out on a vast scale. Likewise, the utilization of the oil in products embodying both 'visible' and 'invisible' oil or fat is very well understood. Similarly, the processing of full-fat or defatted soya-bean meal has now assumed an established pattern. Well-recognized forms of protein concentrates and isolates are readily available on the basis of the processing technology outlined in Fig. I.

Such protein preparations are appropriate for a wide variety of food uses, including texturization into extruded, expanded or spun products. Suitability for specific uses emerges after studying their functional properties. This most vital aspect of their exploitation is now a major pre-occupation, and our lupin products will ultimately be judged by such functional criteria.

\section{Leaf protein (LP)}

As we have already seen, the exploitation of leafy crops, especially crops such as 


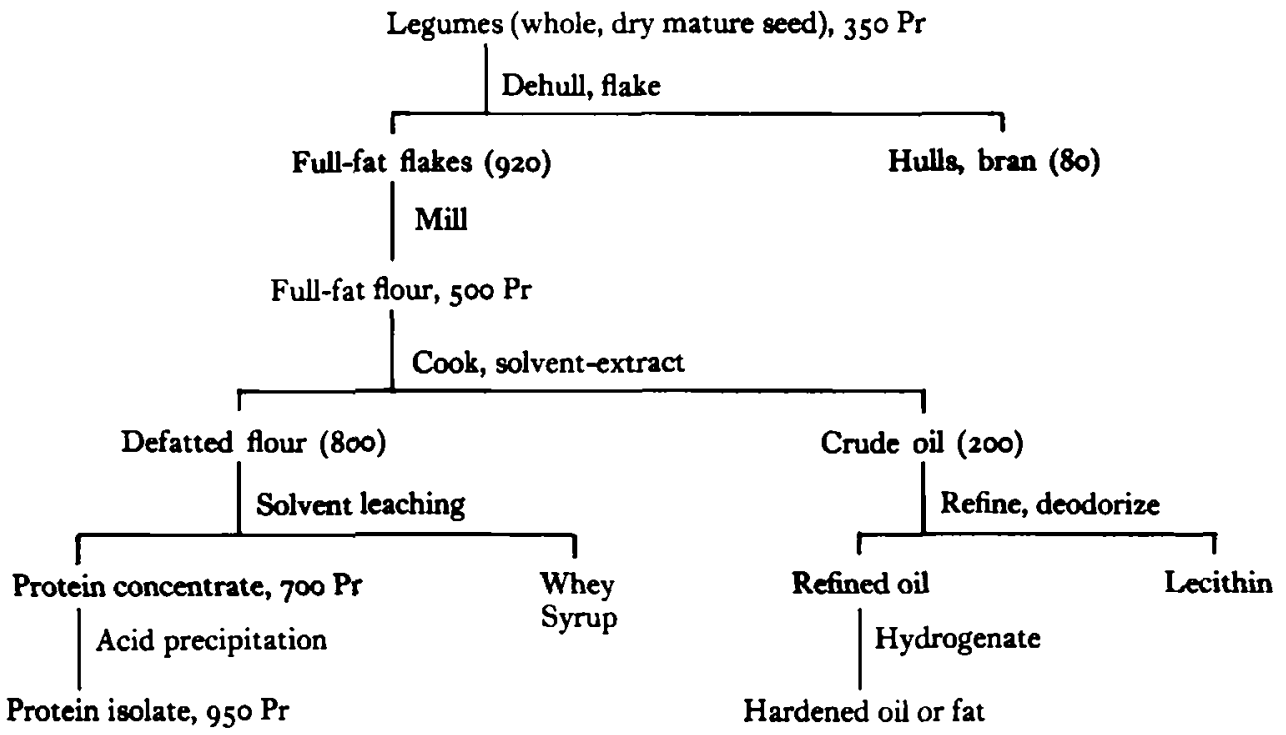

Fig. I. Diagrammatic scheme of legume processing procedures. Values in parentheses indicate yields $(g / \mathrm{kg}), \mathrm{Pr}$, protein levels $(\mathrm{g} / \mathrm{kg})$.

the grasses and lucerne (Medicago sativa) is an attractive possibility for human food production as well as for feedstuffs, in a country with a comparatively mild climate and abundant rainfall (Pirie, 1971). LP production is an alternative to grazing as a means of exploiting pasture.

Fig. 2 outlines the options that are available for the production of protein preparations with potential as human food (Bray, 1977). The mechanical separation of fibrous material from aqueous liquor, 'green juice', is an essential preliminary. The fibrous, partially-dehydrated, solids still contain $140 \mathrm{~g}$ protein $/ \mathrm{kg}$ and have value as a ruminant feedstuff. The separation of protein from the 'green juice' can be effected in several ways, depending on temperature, $\mathrm{pH}$ adjustment or other methods for bringing about protein coagulation.

The most straightforward process, giving the highest yield, is by coagulation at $80^{\circ}$, which gives 'whole-leaf protein concentrate (whole LPC)' a stronglyflavoured green concentrate, which contains both chloroplastic and cytoplasmic material. Some experience has been acquired, especially in India, on the use of this product as a human food supplement, but it seems unlikely to appeal to European tastes. 'Whole LPC', after drying, can be refined by solvent extraction to yield a light-coloured defatted and partially-deodorized product with considerable food potential.

An alternative form of 'green juice' processing begins by precipitating chloroplastic protein at $60^{\circ}$, leaving the more attractive cytoplasmic fraction in solution. Chloroplastic-protein LPC, since it has a very low fibre content, is appropriate as a feedstuff for pigs or poultry. Finally, the cytoplasmic protein is 


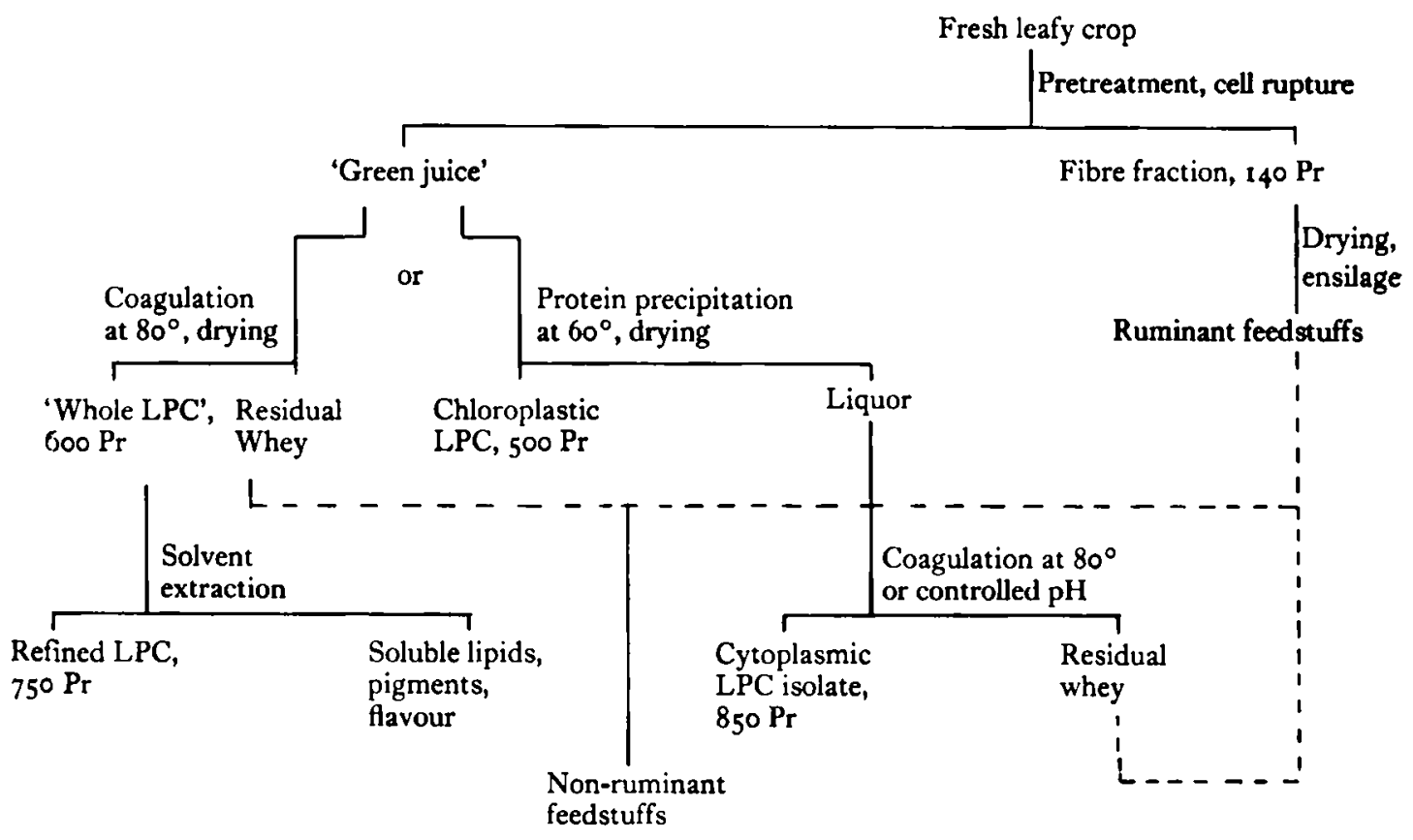

Fig. 2. Diagrammatic scheme of procedures involved in production of leaf protein (LP) preparations and LP concentrates (LPC). Pr, protein levels (g/kg).

separated by adjusting the $\mathrm{pH}$ of the liquor to the isoelectric point, or by heat coagulation at $80^{\circ}$. In both instances, a highly-concentrated, bland white powder can be obtained, closely corresponding to the type of isolate that is obtained as an end product of soya-bean processing. Values we obtained for the compositions of the three alternative fractions are shown in Table 4.

Table 4. Leaf-protein (LP) products" from lucerne (Medicago sativa) $(\mathrm{g} / \mathrm{kg}$ )

\begin{tabular}{lccc}
\multicolumn{1}{c}{ Component } & Crude LPC & Extracted LPC & LP isolate \\
Crude protein (nitrogen $\times 6 \cdot 25)$ & 629 & 764 & 887 \\
Protein & 614 & 754 & nd \\
Ash & 71 & 95 & 4 \\
Lipids & 244 & 18 & 6
\end{tabular}

LPC, LP concentrate; nd, not determined.

-For scheme of preparation, see Fig. 2.

The protein quality of lucerne LPC by analysis shows an excellent amino acid profile, only marginally limiting in methionine and cysteine (Bickoff, 1975). However, caution must be exercised in translating such an observation to biological quality. Biological value is dependent on the crop in question, the method of processing and the intervention of other components such as protease inhibitors or polyphenols. Table 5 shows that, especially in the instance of LP isolate, high values for protein efficiency ratio have been recorded. 
Table 5. Nutritional value of leaf protein (LP) preparations" (after Clifford, 1975)

Preparation
Casein
Crude LPC (calculated)
Solvent-extracted LPC (calculated)
LP isolate: Alone
+2 g MET $/ \mathrm{kg}$
$+2 \mathrm{~g}$ MET $+3 \mathrm{~g} \mathrm{LYS} / \mathrm{kg}$
Chloroplastic LPC: Alone
$+2 \mathrm{~g}$ MET/kg

Protein efficiency ratio $f^{+}$
$2 \cdot 5$
$1 \cdot 6$
$1 \cdot 75$
$2 \cdot 7$
$2 \cdot 9$
3. I
0.4
$2 \cdot 1$

LPC, LP concentrate; MET, methionine; LYS, lysine.

-For scheme of preparation, see Fig. 2.

+Wt gain/amount of protein eaten.

More work on the LP components other than the protein itself is needed before a full evaluation of its nutritional status can be made. The lipid fraction, though substantial, is of little interest as a source of edible oil: it comprises mainly polar structural lipids, though the chlorophylls and carotenoids are significant (Hudson \& Karis, 1973). The carbohydrates have been little investigated: likewise the polyphenols. Correspondingly little is known of the functional properties, especially those of the cruder fractions, or of its potential as a component of processed foods.

\section{Conclusions}

The better use of plant foods is a growth area for research. Most parts of plants have food value, but the best prospects for further development lie in the use of seeds and leaves. Seeds generally, especially oilseeds, with a special emphasis on those which can reliably be cultivated in this country, offer an attractive prospect. A good example is lupinseed.

In the longer term, the exploitation of leafy material by the food processor is a hopeful prospect. Both oilseeds and leaf fractions afford by-products which have value as livestock feedstuffs, with special reference to import-substitution.

\section{REFERENCES}

Bickoff, E. M. (1975). Welpro: Nutritional Evaluation and Current FDA Status, Proc. 12th Tech. Alfalfa Conf., Kansas, 1974.

Bray, W. J. (1977). Separation and Preseroation of Leaf Protein Concentrates and Isolates for Use as Human Food. Proc. Green-Crop Fractionation Conf., Harrogate, 1976. (In the Press.)

Clifford, A. J. (1975). Am. Soc. agric. Engng Mtg paper no. 75-1059.

Hudson, B. J. F., Fleetwood, J. G. \& Zand-Moghaddam, A. (1976). Plant Foods for Man 2, 81. Hudson, B. J. F. \& Karis, I. G. (1973). F. Sci. Fd Agric. 24, 1541.

Joint Consultative Organization, Ministry of Agriculture, Fisheries and Food (1976). Protein Feeds for Farm Livestock in the UK. London: HM Stationery Office.

Pirie, N. W. (editor). (1971). In Leaf Protein: Its Agromony, Preparation, Quality and Use, IBP Handbook no. 20. Oxford: Blactwell Scientific Publications. 